\title{
Autohydrolysis of a partially cyclized mu/nu-carrageenan and structural elucidation of the oligosaccharides by chemical analysis, NMR spectroscopy and UV-MALDI mass spectrometry
}

\author{
Marina Ciancia ${ }^{a}$, Yasuto Sato ${ }^{b}$, Hiroshi Nonami ${ }^{c}$, Alberto S. Cerezo ${ }^{d}$, Rosa Erra-Balsells ${ }^{d}$, \\ and María C. Matulewicz*d \\ ${ }^{a}$ Cátedra de Química Orgánica, CIHIDECAR-CONICET, Departamento de Biología Aplicada y \\ Alimentos, Facultad de Agronomía, Universidad de Buenos Aires, Av. San Martín 4453, 1417 \\ Buenos Aires, Argentina \\ ${ }^{b}$ The United Graduate School of Agricultural Sciences, Ehime University, Tarumi, Matsuyama \\ 790-8566, Japan \\ ${ }^{c}$ Faculty of Agriculture, Ehime University, Tarumi, Matsuyama 790-8566, Japan \\ ${ }^{d}$ Departamento de Química Orgánica, CIHIDECAR-CONICET, Facultad de Ciencias Exactas y \\ Naturales, Universidad de Buenos Aires, Pabellón 2, Ciudad Universitaria, 1428 Buenos Aires, \\ Argentina \\ E-mail: cristina@qo.fcen.uba.ar (MCM)
}

\section{Dedicated to Prof. Rosa M. de Lederkremer on occasion of her $70^{\text {th }}$ anniversary}

\begin{abstract}
A partially cyclized mu/nu-carrageenan from Gigartina skottsbergii was submitted to autohydrolysis and the resulting mixture of oligosaccharides was fractionated using sequential dialysis through tubings of molecular weight cutoff 12000, 3500 and 1000. In this way four fractions were separated and characterized. Structural analysis of the major fraction, obtained from the solution inside the dialysis tubing of molecular weight cutoff 12000 (D120), was carried out. A significant difference was found by ${ }^{13} \mathrm{C}$ NMR spectroscopy and UV-MALDI-TOF mass spectrometry: in the ${ }^{13} \mathrm{C}$ NMR spectrum the reducing end-chain unit was the hydrated aldehyde of 3,6-anhydrogalactose while the UV-MALDI-TOF mass spectrum showed an unimodal distribution of even and odd peaks, suggesting fragmentation of glycosidic linkages.
\end{abstract}

Keywords: Sulfated galactans, carrageenans, autohydrolysis, sulfated oligosaccharides, structural analysis, UV-MALDI-TOF-MS, nor-harmane 


\section{Introduction}

Red seaweeds of the family Gigartinaceae are a rich source of sulfated galactans known as carrageenans which are widely used in food industry as thickening and gelling agents. ${ }^{1}$ Carrageenans consist of an alternating structure of 3-linked $\beta$-D-galactoyranose and 4-linked 3,6anhydro- $\alpha$-D-galactopyranose or $\alpha$-D-galactopyranose. The different hydroxyl groups present in these units can be substituted, mainly with sulfate, but also with single stubs of xylose or methyl groups. ${ }^{1}$ Usually, carrageenans have structures that are a mixture of two or more idealized repeating units (e.g. kappa/iota-carrageenan, mu/nu-carrageenan or a partially cyclized $\mathrm{mu} / \mathrm{nu}$ carrageenan) and are called hybrid carrageenans. ${ }^{2}$ The repeating units of kappa-, iota-, mu- and nu-carrageenans are shown in Figure 1.

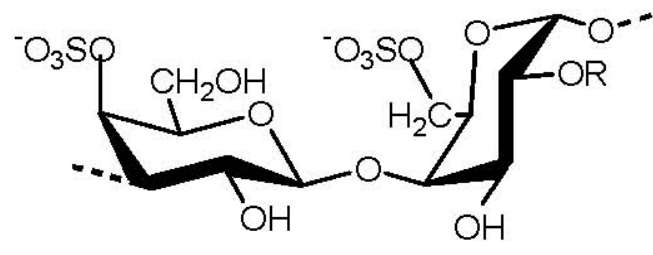

(A)

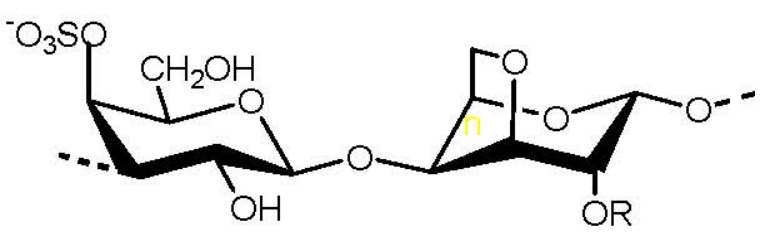

(B)

Figure 1. (A): $\mathrm{R}=\mathrm{H}$, mu-carrageenan; $\mathrm{R}=\mathrm{SO}_{3}{ }^{-}$, nu-carrageenan. (B): $\mathrm{R}=\mathrm{H}$, kappa-carrageenan; $\mathrm{R}=\mathrm{SO}_{3}^{-}$, iota-carrageenan.

In a previous publication ${ }^{3}$, the feasibility of matrix-assisted ultraviolet laser-desorption ionization time-of-flight mass spectrometry (UV-MALDI-TOF-MS) of carrageenans was studied. Several commercial sulfated neocarrabiose oligosaccharides were analyzed in the positive- and negative-ion modes using 2,5-dihydroxybenzoic acid and nor-harmane as matrices. Post-source decay (PSD) experiments were also carried out, and structures of the fragment ions were assigned.

Autohydrolysis reaction has been used to obtain oligosaccharides suitable for structural determination of the parent polysaccharide. ${ }^{4-7}$ This reaction, applied to carrageenans, splits glycosidic linkages between 3,6-anhydro- $\alpha$-galactose 2 -sulfate and $\beta$-galactose 4 -sulfate or between $\alpha$-galactose 2,6-disulfate and $\beta$-galactose 4-sulfate; as soon as these linkages are cleaved, there is a loss of sulfate groups on C-2. The 3,6-anhydro- $\alpha$-D-galactosidic linkages are also cleaved but with a lower reaction rate. ${ }^{4-6}$

A partially cyclized mu/nu-carrageenan from Gigartina skottsbergii, whose structure was previously determined by methylation analysis and NMR spectroscopy, ${ }^{8-10}$ was subjected to autohydrolysis and the mixture of oligosaccharides fractionated. Herein we report the characterization of the fractions and structural analysis of the major one by the combined use of methylation analysis, ${ }^{1} \mathrm{H}$ and ${ }^{13} \mathrm{C}$ NMR spectroscopy and UV-MALDI-TOF-MS. 


\section{Results and Discussion}

The crude carrageenan from cystocarpic plants of Gigartina skottsbergii was fractionated with potassium chloride giving similar amounts of gelling (46.1\%) and non-gelling (53.9\%) carrageenans. $^{8}$ Structural analysis ${ }^{10}$ of the non-gelling carrageenan $\left(1 \mathrm{C}_{3}\right.$, molar ratio galactose:3,6-anhydrogalactose:sulfate 1.00:0.37:1.14) showed that its backbone was mainly constituted by G4S $\rightarrow$ DA (kappa-diad), G4S $\rightarrow$ DA2S (iota-diad) and G4S $\rightarrow$ D2S,6S (nu-diad) with minor contribution of G4S $\rightarrow$ D6S (mu-diad) and other diads (nomenclature of Knutsen et al. $)^{11}$.

$1 \mathrm{C}_{3}$ (molecular weight 198000) was submitted to autohydrolysis and the rate constant of the reaction, calculated from internal 3,6-anhydrogalactose was $6.04 \times 10^{-2} \mathrm{~h}^{-1}$; a value of the same order was previously determined ${ }^{6}$ for a mu/nu-carrageenan from Sarcothalia crispata (Iridaea undulosa). After $11 \mathrm{~h}$ at $60{ }^{\circ} \mathrm{C}$, the acid solution was neutralized and the mixture of oligosaccharides was fractionated using dialysis tubing of molecular weight cutoff 12000 . The dialysis tubing content was concentrated and freeze-dried to give D120 (56.6\% of the recovered) and the dialyzate was subjected to further fractionation with dialysis tubing of molecular weight cutoff 3500 and 1000. Table 1 shows the yields and analyses of the fractions recovered from the dialysis tubings (D120, D35 and D10) and the fraction DW constituted by the oligosaccharides that passed through the dialysis tubing of molecular weight cutoff 1000 .

Table 1. Yields, analyses and monosaccharide composition of the fractions isolated after autohydrolysis of $1 \mathrm{C}_{3}$ and further fractionation of the oligosaccharide mixture with dialysis tubings of different molecular weight cutoff

\begin{tabular}{|c|c|c|c|c|c|c|c|}
\hline \multirow[t]{2}{*}{ Fraction } & Yield $^{\mathrm{a}}$ & $\begin{array}{c}\text { Sulfate } \\
\text { (as } \mathrm{SO}_{3} \mathrm{Na} \text { ) }\end{array}$ & Gal:3,6-AnGal:sulfate & \multicolumn{3}{|c|}{$\begin{array}{c}\text { Monosaccharide composition } \\
\mathrm{mol} \%\end{array}$} & \multirow{2}{*}{$\frac{[\alpha]_{\mathrm{D}}}{\circ}$} \\
\hline & $\%$ & $\%$ & molar ratio ${ }^{b}$ & Gal & AnGal & Xyl & \\
\hline $1 \mathrm{C}_{3}{ }^{\mathrm{c}}$ & & 33.6 & $1.00: 0.45: 1.14$ & 68.9 & 31.1 & $\operatorname{tr}^{\mathrm{d}}$ & +55.1 \\
\hline D120 & 56.6 & 32.7 & $1.00: 0.39: 1.28$ & 71.1 & 27.9 & 1.0 & +41.4 \\
\hline D35 & 6.7 & 35.0 & $1.00: 0.46: 1.37$ & 67.8 & 31.2 & 1.0 & +41.7 \\
\hline D10 & 33.5 & $34.9^{\mathrm{e}}$ & $1.00: 0.23: 1.60$ & 81.3 & 18.7 & $\operatorname{tr}$ & +26.6 \\
\hline DW & 3.1 & 32.8 & $1.00: 0.24: 1.20$ & 79.1 & 18.6 & 2.4 & +47.9 \\
\hline
\end{tabular}

${ }^{a}$ Yields are expressed as percentages of the recovered (76.3\%). ${ }^{\mathrm{b}}$ The Gal:3,6-AnGal ratio was calculated from the monosaccharide composition. ${ }^{\mathrm{c}}$ Included for comparison. ${ }^{\mathrm{d}}$ Percentages lower than $1 \%$ are considered as traces (tr). ${ }^{\mathrm{e}}$ After discounting the inorganic sulfate content.

In order to investigate the homogeneity of the fractions, these were submitted to GPC on Sephadex G-25 using $0.1 \mathrm{M} \mathrm{NaCl}$ as eluant for D35, D10 and DW and $1 \mathrm{M} \mathrm{NaCl}$ for D120; chromatography of all the fractions was also carried on Sephadex G-75 with $0.1 \mathrm{M} \mathrm{NaCl}$. Each 
fraction gave, with both gel filtration media, similar unimodal elution profiles. In addition, D10 was also analyzed by GPC on Sephadex G-25 using $2 \mathrm{M} \mathrm{NaCl}$ and $0.1 \mathrm{M} \mathrm{LiCl}$ but the distributions patterns were alike. Table 2 shows the molecular weights obtained by GPC on Sephadex G-25 and by end-group analysis.

In this Table it is clearly observed that, even though there is a discrepancy between the two methods, the values of molecular weight obtained for D120 and D35 are considerably lower than the expected for these fractions according to their isolation procedure. Fractionation of D10 and DW is probably due to their different degree of sulfation: 130 sulfates every 100 residues for D10 and 97 sulfates every 100 residues for DW.

Table 2. Molecular weight of the different fractions obtained by end-group analysis and GPC

\begin{tabular}{ccc}
\hline Fraction & End group analysis & GPC $^{\mathrm{b}}$ \\
\hline $1 \mathrm{C}_{3}$ & 198000 & n.d. $^{\mathrm{c}}$ \\
$\mathrm{D} 120$ & 1900 & 2670 \\
$\mathrm{D} 35$ & 1340 & 1800 \\
D10 & 770 & 1230 \\
DW & 550 & 1590 \\
\hline
\end{tabular}

${ }^{a}$ Determined by the method of Park and Johnson (see Experimental). ${ }^{\mathrm{b}}$ On Sephadex G-25 and $0.1 \mathrm{M} \mathrm{NaCl}$ as eluant for D35, D10 and DW; for D120 the eluant was $1 \mathrm{M} \mathrm{NaCl}^{\mathrm{c}}$ n.d. $=$ not determined.

Structural analysis of the major fraction $\mathrm{D} 120$ was carried out by ${ }^{1} \mathrm{H}$ and ${ }^{13} \mathrm{C}$ NMR spectroscopy, methylation analysis and UV-MALDI-TOF-MS.

Figure 2 shows the ${ }^{1} \mathrm{H}$-decoupled ${ }^{13} \mathrm{C}$ NMR spectrum of D120 and Table 3 indicates the assignment of the signals.

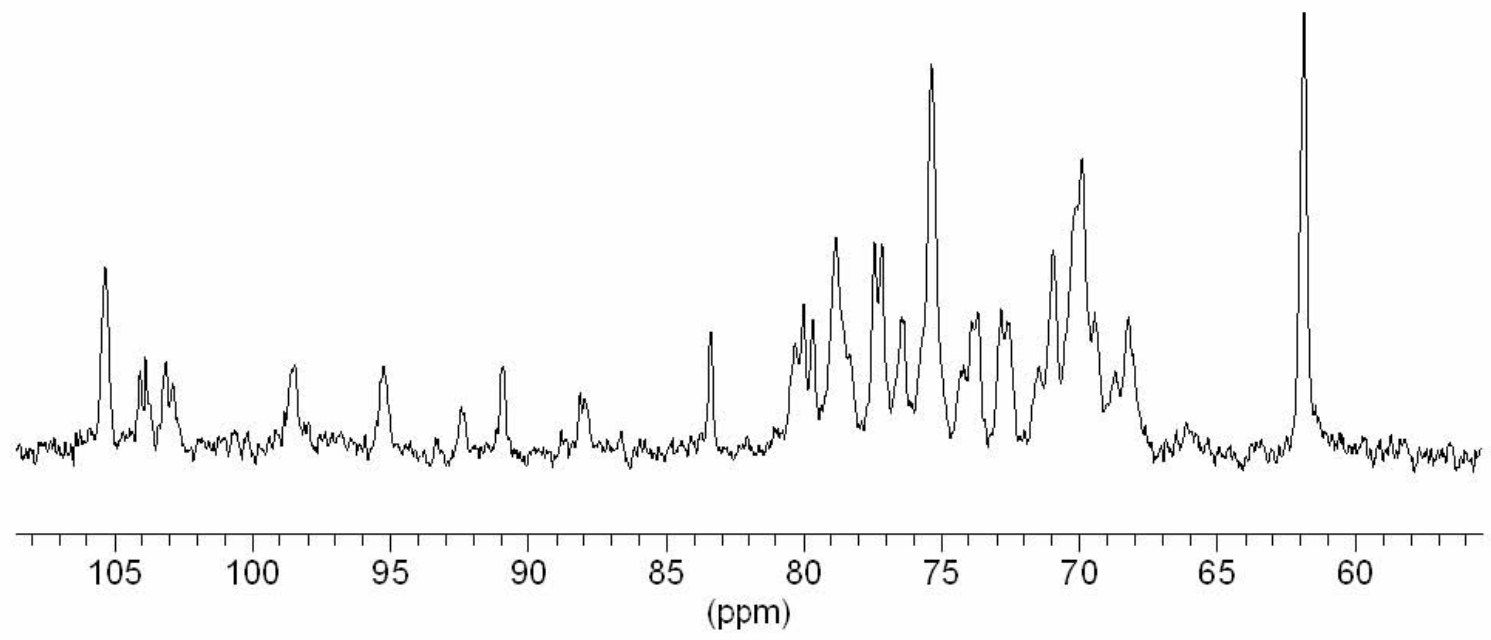

Figure 2. Proton-decoupled ${ }^{13} \mathrm{C}$ NMR spectrum of D120. 
Table 3. Assignment (in ppm) of the ${ }^{13} \mathrm{C}$ NMR spectrum of D120

\begin{tabular}{|c|c|c|c|c|c|c|c|}
\hline \multicolumn{2}{|c|}{ Diad } & $\mathrm{C}-1$ & $\mathrm{C}-2$ & $\mathrm{C}-3$ & $\mathrm{C}-4$ & C-5 & C-6 \\
\hline \multirow[t]{2}{*}{$\mathrm{Mu}-$} & G4S & 105.3 & 71.0 & 78.8 & 73.9 & 75.3 & 61.8 \\
\hline & D6S & 98.4 & 70.0 & $70.5(\mathrm{sh})^{\mathrm{a}}$ & 79.6 & 68.7 & 68.2 \\
\hline \multirow[t]{2}{*}{$\mathrm{Nu}-$} & G4S & 105.3 & 71.0 & 80.3 & 71.5 & 75.3 & 61.8 \\
\hline & $\mathrm{D} 2 \mathrm{~S}, 6 \mathrm{~S}$ & 98.6 & 76.3 & 68.7 & 79.6 & 68.7 & 68.2 \\
\hline \multirow[t]{2}{*}{ Kappa- } & G4S & 103.1 & 69.9 & 78.8 & 74.2 & 75.3 & 61.8 \\
\hline & DA & 95.3 & 70.1 & 79.6 & 78.8 & 77.1 & 69.9 \\
\hline \multirow[t]{2}{*}{ Iota- } & G4S & 102.9 & 69.9 & 77.1 & 72.8 & 75.3 & 61.8 \\
\hline & DA2S & 92.4 & 75.3 & 78.3 & 78.8 & 77.4 & $70.5(\mathrm{sh})$ \\
\hline \multicolumn{8}{|c|}{ Carrabiose 4'-sulfate } \\
\hline & G4S & 103.9 & 72.5 & 72.8 & 77.4 & 75.3 & 61.8 \\
\hline & $\mathrm{DA}^{\mathrm{b}}$ & 90.9 & 73.7 & 83.4 & 88.0 & 76.4 & 73.9 \\
\hline \multicolumn{2}{|c|}{ Single stubs $\beta$-D-Xyl } & 104.1 & & & & 66.1 & \\
\hline
\end{tabular}

${ }^{\mathrm{a}} \mathrm{sh}=$ shoulder. ${ }^{\mathrm{b}}$ Hydrated aldehyde.

In this spectrum, the diads corresponding to kappa-, iota-, mu- and nu-structures were clearly observed, ${ }^{10,12}$ with prevalence of the mu- and kappa-diads. Besides, peaks of carrabiose 4'sulfate and oligosaccharides containing carrabiose units were also important, ${ }^{13}$ and no anomeric resonances due to reducing end-chain galactose were detected. This result is in agreement with the ${ }^{1} \mathrm{H}$ NMR spectrum of this fraction where only weak signals at 5.53 and $5.30 \mathrm{ppm}$, due to the $\mathrm{H}-1$ of $\alpha$-D-galactose 2,6-disulfate and 3,6-anhydrogalactose 2-sulfate, both linked to $\beta$-Dgalactose 4-sulfate, were found. ${ }^{10}$

Reduced D120 was converted into the triethylammonium salt and methylated according the method of Hakomori. ${ }^{14,15}$ Table 4 shows the composition of the permethylated product.

Table 4. Composition (mol\%) of monosaccharides produced by permethylation and hydrolysis of D120

\begin{tabular}{|c|c|}
\hline Monosaccharide & D120 \\
\hline $2,3,4,6-\mathrm{Me}_{4} \mathrm{Gal}$ & 1.1 \\
\hline 2-Me AnGal & 19.5 \\
\hline $2,4,6-\mathrm{Me}_{3} \mathrm{Gal}$ & 7.8 \\
\hline $2,3,6-\mathrm{Me}_{3} \mathrm{Gal}$ & 6.6 \\
\hline 2,6- $\mathrm{Me}_{2} \mathrm{Gal}$ & 50.7 \\
\hline AnGal & 5.3 \\
\hline 2,3-- $\mathrm{Me}_{2} \mathrm{Gal}$ & 2.4 \\
\hline 2-Me Gal & 2.1 \\
\hline 3-Me Gal & 3.0 \\
\hline Glc & 1.5 \\
\hline
\end{tabular}


The galactose:3,6-ahydrogalactose molar ratio, calculated from Table 4 is 1.00:0.34, very similar to that of the non-methylated fraction (1.00:0.39), and if it is considered that the 2,3,6-tri$O$-methylgalactose derives from non-reducing end-chain $\beta$-galactose 4 -sulfate units, the molecular weight is $\sim 3000$, slightly higher to that obtained by GPC. In addition, the lower galactose:3,6-ahydrogalactose molar ratio calculated from Table 4 was consistent with the loss of permethylated small carrabiose oligosaccharides (see later the analysis of the UV-MALDI-TOF mass spectrum) during the dialysis of the methylation procedure. It should be noted that no methylated derivatives corresponding to the 4-linked reducing end-chain 3,6-anhydrogalactose or galactose 6-sulfate residues were detected by gas-chromatography analysis of the alditol acetates.

D120 was also analyzed by UV-MALDI-TOF-MS using 2,5-dihydroxybenzoic acid and norharmane as matrices. Experiments were carried out in the linear and reflectron modes and, as routine, in the positive- and negative-ion modes; good spectra were only obtained with norharmane in the negative-ion mode. Table 5 shows the $\mathrm{m} / \mathrm{z}$ values and the assignment of the main peaks observed in the linear mode spectrum of this fraction (Figure 3). For the assignment, the information acquired by methylation analysis and ${ }^{13} \mathrm{C}$ NMR spectroscopy was essential. Thus, it was assumed that: a) all the 3-linked units were sulfated in the 4-position (G4S); b) the major kappa- (G4S $\rightarrow$ DA) and mu-diads (G4S $\rightarrow$ D6S) were the only observed; and c) the 4-linked reducing end-chain residues should be, according to previous reports ${ }^{4-6}$ on the autohydrolysis reaction, the hydrated aldehyde of 3,6-anhydrogalactose (reducing end-chain DA) or galactose 6sulfate (reducing end-chain D6S), with high prevalence of the former according to the ${ }^{13} \mathrm{C} N M R$ spectrum.

Table 5. UV-MALDI-TOF-MS of D120

\begin{tabular}{cc}
\hline $\mathrm{m} / \mathrm{z}$ & Assignment \\
\hline 727.6 & {$\left[\mathrm{G} 4 \mathrm{~S} \rightarrow \mathrm{DA} \rightarrow \mathrm{G} 4 \mathrm{~S} \rightarrow \mathrm{DA}-\mathrm{NaSO}_{3}+\mathrm{H}-\mathrm{Na}\right]^{-}$} \\
889.8 & {$\left[\mathrm{G} 4 \mathrm{~S} \rightarrow \mathrm{D} 6 \mathrm{~S} \rightarrow \mathrm{G} 4 \mathrm{~S} \rightarrow \mathrm{DA} \rightarrow \mathrm{G} 4 \mathrm{~S}-3 \mathrm{NaSO}_{3}+3 \mathrm{H}-\mathrm{Na}\right]^{-}$} \\
1052.0 & {$\left[\mathrm{G} 4 \mathrm{~S} \rightarrow \mathrm{D} 6 \mathrm{~S} \rightarrow \mathrm{G} 4 \mathrm{~S} \rightarrow \mathrm{D} 6 \mathrm{~S}-\mathrm{Na}^{-}\right.$} \\
1214.3 & {$\left[\mathrm{G} 4 \mathrm{~S} \rightarrow \mathrm{D} 6 \mathrm{~S} \rightarrow \mathrm{G} 4 \mathrm{~S} \rightarrow \mathrm{D} 6 \mathrm{~S} \rightarrow \mathrm{G} 4 \mathrm{~S}-\mathrm{NaSO}_{3}+\mathrm{H}-\mathrm{Na}\right]^{-}$} \\
1376.5 & {$\left[\mathrm{G} 4 \mathrm{~S} \rightarrow \mathrm{D} 6 \mathrm{~S} \rightarrow \mathrm{G} 4 \mathrm{~S} \rightarrow \mathrm{D} 6 \mathrm{~S} \rightarrow \mathrm{G} 4 \mathrm{~S} \rightarrow \mathrm{DA}-\mathrm{NaSO}_{3}+\mathrm{H}-\mathrm{Na}\right]^{-}$} \\
1538.5 & {$\left[\mathrm{G} 4 \mathrm{~S} \rightarrow \mathrm{D} 6 \mathrm{~S} \rightarrow \mathrm{G} 4 \mathrm{~S} \rightarrow \mathrm{D} 6 \mathrm{~S} \rightarrow \mathrm{G} 4 \mathrm{~S} \rightarrow \mathrm{D} 6 \mathrm{~S} \rightarrow \mathrm{G} 4 \mathrm{~S}-3 \mathrm{NaSO}_{3}+3 \mathrm{H}-\mathrm{Na}\right]^{-}$} \\
1700.5 & {$\left[\mathrm{G} 4 \mathrm{~S} \rightarrow \mathrm{D} 6 \mathrm{~S} \rightarrow \mathrm{G} 4 \mathrm{~S} \rightarrow \mathrm{D} 6 \mathrm{~S} \rightarrow \mathrm{G} 4 \mathrm{~S} \rightarrow \mathrm{D} 6 \mathrm{~S} \rightarrow \mathrm{G} 4 \mathrm{~S} \rightarrow \mathrm{DA}-3 \mathrm{NaSO}_{3}+3 \mathrm{H}-\mathrm{Na}\right]^{-}$} \\
1862.6 & {$\left[\mathrm{G} 4 \mathrm{~S} \rightarrow \mathrm{D} 6 \mathrm{~S} \rightarrow \mathrm{G} 4 \mathrm{~S} \rightarrow \mathrm{D} 6 \mathrm{~S} \rightarrow \mathrm{G} 4 \mathrm{~S} \rightarrow \mathrm{D} 6 \mathrm{~S} \rightarrow \mathrm{G} 4 \mathrm{~S} \rightarrow \mathrm{D} 6 \mathrm{~S} \rightarrow \mathrm{G} 4 \mathrm{~S}-5 \mathrm{NaSO}_{3}+5 \mathrm{H}-\mathrm{Na}\right]^{-}$} \\
2024.7 & {$\left[\mathrm{G} 4 \mathrm{~S} \rightarrow \mathrm{D} 6 \mathrm{~S} \rightarrow \mathrm{G} 4 \mathrm{~S} \rightarrow \mathrm{D} 6 \mathrm{~S} \rightarrow \mathrm{G} 4 \mathrm{~S} \rightarrow \mathrm{D} 6 \mathrm{~S} \rightarrow \mathrm{G} 4 \mathrm{~S} \rightarrow \mathrm{D} 6 \mathrm{~S} \rightarrow \mathrm{G} 4 \mathrm{~S} \rightarrow \mathrm{DA}-5 \mathrm{NaSO}_{3}+5 \mathrm{H}-\mathrm{Na}\right]^{-}$} \\
2186.9 & {$\left[\mathrm{G} 4 \mathrm{~S} \rightarrow \mathrm{D} 6 \mathrm{~S} \rightarrow \mathrm{G} 4 \mathrm{~S} \rightarrow \mathrm{D} 6 \mathrm{~S} \rightarrow \mathrm{G} 4 \mathrm{~S} \rightarrow \mathrm{D} 6 \mathrm{~S} \rightarrow \mathrm{G} 4 \mathrm{~S} \rightarrow \mathrm{D} 6 \mathrm{~S} \rightarrow \mathrm{G} 4 \mathrm{~S} \rightarrow \mathrm{D} 6 \mathrm{~S} \rightarrow \mathrm{G} 4 \mathrm{~S}-7 \mathrm{NaSO}_{3}+7 \mathrm{H}-\mathrm{Na}\right]^{-}$} \\
2349.6 & {$\left[\mathrm{G} 4 \mathrm{~S} \rightarrow \mathrm{D} 6 \mathrm{~S} \rightarrow \mathrm{G} 4 \mathrm{~S} \rightarrow \mathrm{D} 6 \mathrm{~S} \rightarrow \mathrm{G} 4 \mathrm{~S} \rightarrow \mathrm{D} 6 \mathrm{~S} \rightarrow \mathrm{G} 4 \mathrm{~S} \rightarrow \mathrm{D} 6 \mathrm{~S} \rightarrow \mathrm{G} 4 \mathrm{~S} \rightarrow \mathrm{D} 6 \mathrm{~S} \rightarrow \mathrm{G} 4 \mathrm{~S} \rightarrow \mathrm{DA}-7 \mathrm{NaSO}_{3}+7 \mathrm{H}-\mathrm{Na}\right]^{-}$} \\
\hline
\end{tabular}

${ }^{a}$ Linear negative-ion mode; nor-harmane as matrix.

The $\mathrm{m} / \mathrm{z}$ values of the main peaks, assigned in Table 5 , corresponded to $[\mathrm{M}-\mathrm{Na}]^{-}$or to $[\mathrm{M}+$ $\left.n \mathrm{H}-n \mathrm{NaSO}_{3}-\mathrm{Na}\right]^{-}$. Extensive desulfation has also been previously reported for sulfated neocarrabiose oligosacharides with nor-harmane as matrix. ${ }^{3,16}$ In addition, spectral analysis was 
consistent again with a maximum loss of $(x-1)$ sulfate groups, where $x$ is the number of sulfates in the analyte, suggesting that the non-ionized sulfate groups are more easily lost than the stabilized sulfate anion or that the monocharged anion with only one sulfate group is the most stable in the UV-MALDI process. ${ }^{3}$

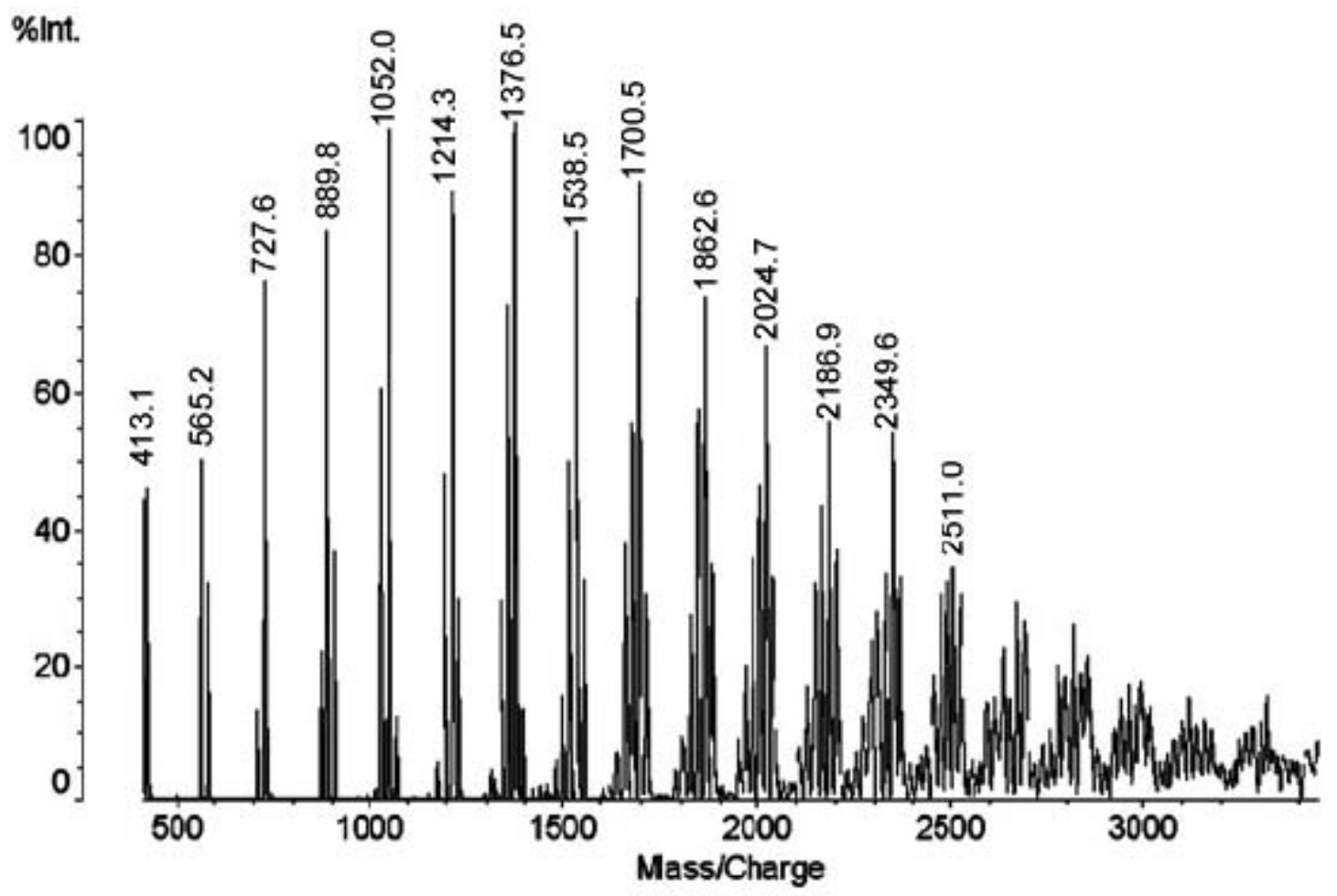

Figure 3. Negative-ion mode UV-MALDI-TOF mass spectrum of D120 carried out in the linear mode using nor-harmane as matrix. Peaks at $\mathrm{m} / \mathrm{z} 413.1$ and 565.2 Da were not assigned.

For each peak of the asymmetrical curve shown in Figure 3, a minor signal at $\mathrm{m} / \mathrm{z}-18 \mathrm{Da}$ was observed. This difference could be either attributed to: a) the replacement in the oligosaccharide structure of a galactose by a 3,6-anhydrogalactose unit and/or b) the loss of water from the reducing end-chain hydrated aldehyde of 3,6-anhydrogalactose. It is noteworthy that no loss of water was previously observed in the mass spectra of the sulfated neocarrabiose oligosaccharides determined in the same conditions. ${ }^{3}$ This asymmetrical profile suggested a mass-dependent discrimination ${ }^{17}$ for $\mathrm{m} / \mathrm{z}$ higher than $2349.6 \mathrm{Da}$. Some of the peaks also showed a minor signal at $m / z+18$ Da, which could derive from the replacement of a 3,6anhydrogalactose unit by a non- sulfated galactose in the oligosaccharide structure.

Besides, it is important to note that there is an alternant sequence of signals corresponding to oligosaccharides with even $(\mathrm{m} / \mathrm{z}$ 727.6, 1052.0, 1376.5, 1700.5, 2024.7 and 2349.6 Da) and odd $(\mathrm{m} / \mathrm{z} 889.8,1214.3,1538.5,1862.6$ and $2186.9 \mathrm{Da})$ number of residues. However, the most intense peaks of the spectrum correspond to oligosaccharides with even number of residues.

The presence of fragments with an even and odd number of residues could indicate that, 
during the autohydrolysis reaction, some $\beta$-galactosidic linkages were cleaved, or that a significant amount of 3,6-anhydrogalactose residues was degraded. However, this result is not in agreement with the ${ }^{13} \mathrm{C}$ NMR spectrum where it is clearly observed that the reducing end-chain unit is the hydrated aldehyde of 3,6-anhydrogalactose. Therefore, the presence of oligosaccharides with an odd number of residues would arise in the UV-MALDI process ${ }^{17}$ probably due to glycosidic $C$-cleavages ${ }^{18}$ which involve breaking the bond between the reducing end-chain hydrated aldehyde of 3,6-anhdrogalactose and the adjacent galactose 4-sulfate unit. In the negative-ion mode UV-MALDI-TOF reflectron mass spectrum of neocarrahexaose $4^{1}, 4^{3}, 4^{5}$ trisulfate, a $C_{5}$-ion was detected; ${ }^{3}$ however, this fragmentation involved the cleavage between the reducing end-chain galactose 4-sulfate and the adjacent 3,6-anhydrogalactose residue.

In conclusion, though the oligosaccharides present in D120 are of low molecular weight, their regular structure would promote aggregation precluding dialysis through tubing of molecular weight cutoff 12000. In addition this is the first report on UV-MALDI-TOF-MS of sulfated oligosaccharides with reducing end-chain 3,6-anhydrogalactose units. Furthermore, norharmane showed again to be a high efficient UV-MALDI matrix for desorption/ionization of sulfated oligosaccharides in negative-ion mode.

\section{Experimental Section}

Materials. Partially cyclized $\mathrm{mu} /$ nu-carrageenan $1 \mathrm{C}_{3}$ is the fraction soluble in $2.0 \mathrm{M}$ potassium chloride obtained by fractionation of the carrageenans extracted from cystocarpic plants of the red seaweed Gigartina skottsbergii. ${ }^{8}$

Dextran sulfates of average molecular weight 8000, 10000, and 500000, as well as neocarrabiose $4^{1}$-sulfate (N-8511), neocarratetraose $4^{1}, 4^{3}$-disulfate (N 8136), neocarrahexaose $2^{4}, 4^{1}, 4^{3}, 4^{5}$ tetrasulfate ( $\mathrm{N}$ 8139), neocarraoctaose $4^{1}, 4^{3}, 4^{5}, 4^{7}$-tetrasultate ( $\mathrm{N} 8393$ ), neocarradodecaose $4^{1}, 4^{3}, 4^{5}, 4^{7}, 4^{9}, 4^{11}$-hexasulfate (N 8511) were obtained from Sigma Chemical Co. (St. Louis, MO).

General Procedures. Carbohydrate content was analyzed by phenol-sulfuric acid method ${ }^{19}$ without previous hydrolysis of the polysaccharide, while 3,6-anhydrogalactose was estimated by the resorcinol method ${ }^{20}$. Sulfate was measured by the turbidimetric method of Dodgson and Price. ${ }^{21}$ Molecular weights were calculated by the determination of the reducing end-groups using the colorimetric method of Park and Johnson. ${ }^{22}$

Reductive hydrolysis of the samples and acetylation of alditol mixtures was performed as described elsewhere. ${ }^{14}$ GLC of alditol acetates was carried out on a Hewlett-Packard 5890 A gas chromatograph equipped with a flame-ionization detector and fitted with a fused-silica column $(0.25 \mathrm{~mm}$ i.d. $\mathrm{x} 30 \mathrm{~m})$ WCOT-coated with $0.20 \mu \mathrm{m}$ film of SP-2330. Chromatography was perfomed: a) from $200^{\circ} \mathrm{C}$ to $230{ }^{\circ} \mathrm{C}$ at $1{ }^{\circ} \mathrm{C} \mathrm{min}^{-1}$, followed by a 30 -min hold for alditol acetates, and b) with an initial 2-min hold at $180{ }^{\circ} \mathrm{C}$, then at $2{ }^{\circ} \mathrm{C} \mathrm{min}{ }^{-1}$ to $210^{\circ} \mathrm{C}$, then at $1{ }^{\circ} \mathrm{C} \mathrm{min}{ }^{-1}$ from $210{ }^{\circ} \mathrm{C}$ to $230{ }^{\circ} \mathrm{C}$, followed by a 30 -min hold for partially methylated alditol acetates. $\mathrm{N}_{2}$ was 
used as the carrier gas at a flow rate of $1 \mathrm{~mL} \mathrm{~min}^{-1}$, the split ratio was 80:1 and the head pressure 15 psi. The injector and detector temperature was $240{ }^{\circ} \mathrm{C}$.

Conversion of GLC areas to molar basis was calculated for the partially methylated alditol acetates according to the effective carbon response theory. ${ }^{23}$ For $1,2,4,5$-tetra-O-acetyl-3,6anhydrolgalactitol and 1,4,5-tri-O-acetyl-3,6-anhydro-2-O-methylgalactitol values of 0.72 and 0.64 , respectively, were used. ${ }^{14}$

GLC-MS of the methylated alditol acetates was carried out on a GCMS-QP 5050A gas chromatograph/mass spectrometer (Shimadzu Corporation). Chromatography was performed on the SP-2330 capillary column using the programme temperature (b). The He total flow rate was $4.4 \mathrm{~mL} \mathrm{~min}-1$, the head pressure $12 \mathrm{psi}$, the injector temperature $250{ }^{\circ} \mathrm{C}$ and the split ratio $10: 1$. Mass spectra were recorded over a mass range of 30-600 amu, using a ionization potencial of $70 \mathrm{eV}$.

\section{Analytical autohydrolysis of $\mathbf{1 C}_{\mathbf{3}}$}

The sample (214 $\mathrm{mg})$ was dissolved in water $(21 \mathrm{~mL})$ and was passed through an Amberlite IR$120\left(\mathrm{H}^{+}\right)$column $(10 \times 1 \mathrm{~cm}$ i.d. $)$; the final volume was $60 \mathrm{~mL}$. The solution was shaken at $60{ }^{\circ} \mathrm{C}$ and aliquots $(0.5 \mathrm{~mL})$ were taken at different times, neutralized with calcium carbonate and reduced with sodium borohydride. The 3,6-anhydrogalactose content was measured on the reduced solutions and the values were used to determine the rate constant. After $11 \mathrm{~h}$, the remaining solution was allowed to reach room temperature and neutralized with sodium carbonate. The solution gave an absorbance of 0.191 at $280 \mathrm{~nm}$, indicating than less than $0.5 \%$ of the total 3,6-anhydrogalactose was degraded to hydroxymethylfurfural. The solution was concentrated and freeze-dried.

\section{Preparative autohydrolysis of $\mathbf{1 C}_{3}$}

The sample $(2.5 \mathrm{~g})$ was dissolved in water $(250 \mathrm{~mL})$ and was passed throght an Amberlite IR$120\left(\mathrm{H}^{+}\right)$column $(25 \times 2 \mathrm{~cm}$ i.d. $)$; the final volume was $500 \mathrm{~mL}$. The solution was shaked at $60{ }^{\circ} \mathrm{C}$ for $11 \mathrm{~h}$, then it was allowed to reach room temperature, neutralized with sodium carbonate, and concentrated to give a volume of $125 \mathrm{~mL}$.

\section{Fractionation using dialysis tubing of different molecular weight cutoff}

The concentrated solution was dialyzed (Spectra/Por molecular weight cutoff 12000-14000) against distilled water $(2.5 \mathrm{~L})$ with constant agitation during $18 \mathrm{~h}$. The procedure was repeated once more with a new batch of distilled water $(1 \mathrm{~L})$, and the dialysis tubing content was concentrated and freeze-dried to give D120 (1.08 g). The two dialyzates were pooled and the resulting solution $(3.5 \mathrm{~L}$ ) was concentrated to $80 \mathrm{~mL}$ and dialyzed (Spectra/Por molecular weight cutoff 3500$)$ against distilled water $(700 \mathrm{~mL})$. The same procedure described before led to the isolation of D35 $(135 \mathrm{mg})$. The dialyzates obtained in this step were submitted to a similar procedure (Spectra/Por molecular cutoff 1000). The solution inside the dialysis tubing was concentrated and freeze-dried to give D10 $(640 \mathrm{mg})$ and the dialyzates gave DW (59 $\mathrm{mg})$ after carrying out the same procedure. 


\section{Reduction of the samples for methylation analysis and GPC}

The sample was dissolved in a minimum amount of water and sodium borohydride was added. The solution was left overnight at room temperature and the excess of reductant was quenched with acetic acid. The mixture was heated to $40{ }^{\circ} \mathrm{C}$ and evaporated to dryness with a stream of dry air. Methanol $(4 \times 0.5 \mathrm{~mL})$ was added and the solution was evaporated.

\section{Methylation analysis}

Reduced D120 (6 mg) was converted into the corresponding triethylammonium salt and methylated according to Hakomori, as described elsewhere. ${ }^{14,15}$ The methylated derivative was recovered by dialysis (Spectra/Por molecular weight cutoff 1000) and freeze-drying.

\section{GPC on Sephadex G-25 and G-75}

The sample $(10 \mathrm{mg})$ was chromatographed on a Sephadex G-25 column $(74 \times 1 \mathrm{~cm}$ i.d.) using (0.1 M, $1 \mathrm{M}$, or $2 \mathrm{M}$ ) sodium chloride or $0.1 \mathrm{M} \mathrm{LiCl}$ as eluants; with Sephadex G-75 the eluant was $0.1 \mathrm{M} \mathrm{NaCl}$. Fractions of $1.2 \mathrm{~mL}$ were collected and aliquots were assayed by the phenolsulfuric acid method. The dextran sulfates and the sulfated oligosaccharides described in Materials were cromatographed in the same conditions as the samples.

\section{${ }^{1} \mathrm{H}$ NMR and ${ }^{13} \mathrm{C}$ NMR spectroscopy}

$50-\mathrm{MHz}{ }^{13} \mathrm{C}$ NMR ${ }^{1} \mathrm{H}$-decoupled spectrum of D120 (30 mg) was recorded at room temperature on a Bruker AC 200 spectrometer, in $\mathrm{H}_{2} \mathrm{O}-\mathrm{D}_{2} \mathrm{O}$ 1:1 solution $(0.5 \mathrm{~mL})$, using a 5-mm NMR tube and with external reference to TMS. Specific parameters included a pulse angle of $90^{\circ}$, an acquisition time of $0.74 \mathrm{~s}$, no pulse delay, a spectral width of $11 \mathrm{KHz}$ and 150000 scans.

For the ${ }^{1} \mathrm{H}$ NMR spectrum, the sample $(10 \mathrm{mg})$ was dissolved in $\mathrm{D}_{2} \mathrm{O}(0.5 \mathrm{~mL})$ and a $5-\mathrm{mm}$ NMR tube was used. The spectrum was recorded on a Bruker AM 500 spectrometer, at room temperature using a spectral width of $6.4 \mathrm{kHz}, 90^{\circ}$ pulse, an acquisition time of $5.1 \mathrm{~s}$, for 240 scans. Acetone was used as internal standard, at $2.20 \mathrm{ppm}$.

\section{UV-MALDI-TOF-MS}

Matrix chemicals. The $\beta$-carboline (9H-pyrido[3,4-b]indole) nor-harmane, 2,5dihydroxybenzoic acid (DHB, gentisic acid) and 3,5-dimethoxy-4-hydroxycinnamic acid (SA, sinapinic acid; used for protein calibrants) were obtained from Aldrich-Chemical Co.

Calibrant chemicals. Caffeine (MW 149.19); tetrabutylammonium bromide (MW 322.37); $\beta$ estradiol-3-sulfate-17-glucuronide dipotassium salt (MW 604.75); $\alpha$-cyclodextrin (cyclohexaamylose, MW 972.9); $\beta$-cyclodextrin (cycloheptaamylose, MW 1135.0); $\gamma$ cyclodextrin (cyclooctaamylose, MW 1297.1); angiotensin I (MW 1296.49); neurotensin (N 6383) and bovine insulin (I 5500, MW 5733.5) were purchased from Sigma-Aldrich.

Solvents. $\mathrm{MeOH}$ and $\mathrm{MeCN}$ (Sigma-Aldrich HPLC grade) were used as purchased without further purification. Water of very low conductivity (Milli Q grade; $56-59 \mathrm{nS} / \mathrm{cm}$ with PURIC-S, ORUGANO Co., Ltd., Tokyo, Japan) was used.

Instruments. Measurements were performed using: i) Shimadzu Kratos, Kompact MALDI 4 (Pulsed Extraction) laser-desorption time-of-flight mass spectrometer (Shimadzu, Kyoto, Japan), ii) PerSeptive Biosystems Voyager DE-STR laser-desorption time-of-flight mass spectrometer, 
both equipped with pulsed nitrogen laser $(\lambda \mathrm{em}=337 \mathrm{~nm}$; pulse width $=3 \mathrm{~ns}$ ), tunable pulseddelayed extraction (PDE) and PSD (MS/MS device) modes, as described elsewhere. ${ }^{24-26}$

Experiments were performed using firstly the full range setting for laser firing position in order to select the optimal position for data collection, and secondly fixing the laser firing position in the sample sweet spots. The sample was irradiated just above the threshold laser power for obtaining molecular ions and with higher laser power for studying cluster formation. Thus, the irradiation used for producing a mass spectrum was analyte dependent. Usually 50 spectra were accumulated. The sample was measured in the linear and reflectron modes, in both positive- and negative-ion modes.

Probe supports. The stainless steel polished surface twenty-sample-slides were purchased from Shimadzu Co., Japan (P/N 670-19109-01). Polished surface slides were used in order to get better images for morphological analysis in a stereoscopic microscope (NIKON Optiphot, Tokyo, Japan; magnification $400 \mathrm{x}$ ) and a high-resolution digital microscope (Keyence VH6300, Osaka, Japan; magnification $800 \mathrm{x}$ ).

199-Welled gold sample plates (P/N V700401) were used in the PerSeptive Biosystems Voyager DE-STR mass spectrometer; samples were placed at locations which were mirrorpolished.

Sample preparation. Matrix stock solutions were made by dissolving $2 \mathrm{mg}$ of the selected compound in $0.2 \mathrm{~mL}$ of $\mathrm{MeOH}-\mathrm{H}_{2} \mathrm{O}(1: 1, \mathrm{v} / \mathrm{v})$ or in $0.2 \mathrm{~mL}$ of $\mathrm{MeCN}-\mathrm{H}_{2} \mathrm{O}(2: 3, \mathrm{v} / \mathrm{v})$. Analyte solutions were freshly prepared by dissolving the carbohydrates $(1 \mathrm{mg})$ in pure water $(0.5 \mathrm{~mL})$. Best results were afforded when the matrix solutions were prepared in $\mathrm{MeOH}-\mathrm{H}_{2} \mathrm{O}$.

To prepare the analyte-matrix deposit two methods were used: Method A (thin-film layer method) and Method B., ${ }^{3,24-26}$ Best results were obtained using nor-harmane as matrix and Method B. In this method, the analyte stock solution was mixed with the matrix solution in 1:4 $\mathrm{v} / \mathrm{v}$ ratio. A $0.5 \mu \mathrm{L}$ aliquot of this analyte-matrix solution was deposited onto the stainless steel probe tip and dried with a stream of forced room temperature air. Then, an additional portion of $0.5 \mu \mathrm{L}$ was applied to the dried solid layer on the probe, causing it to re-dissolve partially, and the solvent was removed by blowing air.

Spectrum calibration. Spectra were calibrated by use of external calibration reagents. In the linear and reflectron modes: a) commercial proteins (neurotensin; insulin) with SA as matrix in positive- and negative-ion mode, and b) $\alpha$-, $\beta$ - and $\gamma$-cyclodextrins with nor-harmane as matrix in positive- and in negative-ion modes. The Kratos Kompact calibration program and the Voyager DE-STR calibration program were respectively used.

The ultraviolet laser-desorption ionization mass spectrum (UV-LDI-MS) of nor-harmane was determined with both instruments and in the negative-ion mode; the signals observed in the range of $m / z$ 300-2500 Da are: $m / z$ 1066, 793, 657, 560, 501, 435, 426, 396 and 385 . 


\section{Acknowledgements}

The authors are indebted to the National Research Council of Argentina (CONICET; PIP 446/98, 904/98 and 2192/00), the Agencia Nacional de Promoción Científica y Tecnológica (ANPCYT; PICT02 6-12312 and PICT03 6-14237) and the University of Buenos Aires (UBA; X016, X022, X325) for financial support. Alberto S. Cerezo (under contract), Marina Ciancia, Rosa ErraBalsells and María C. Matulewicz are Research Members of CONICET. UV-MALDI-TOF-MS was performed as part of the Academic Agreement between Rosa Erra-Balsells (FCEyN-UBA, Argentina) and Hiroshi Nonami (CA-EU, Japan) with the facilities of the High Resolution Liquid Chromatography-integrated Mass Spectrometer System of the United Graduated School of Agricultural Sciences (Ehime University, Japan).

\section{References}

1. Usov, A. I. Food Hydrocolloids 1992, 6, 9.

2. Stortz, C. A.; Cerezo, A. S. Curr. Top. Phytochem. 2000, 4, 121.

3. Fukuyama, Y; Ciancia, M.; Nonami, H.; Cerezo, A. S.; Erra-Balsells, R.; Matulewicz, M.C. Carbohydr. Res. 2002, 337, 1553.

4. Stortz, C. A.; Cerezo, A. S. Carbohydr. Res. 1987, 166, 317.

5. Stortz, C. A.; Cerezo, A. S. Int. J. Biol. Macromol. 1991, 13, 101.

6. Ciancia, M.; Matulewicz, M. C.; Stortz, C. A.; Cerezo, A. S. Int. J. Biol. Macromol. 1991, 13, 337.

7. Noseda, M. D.; Cerezo, A. S. Int. J. Biol. Macromol. 1993, 15, 177.

8. Matulewicz, M. C.; Ciancia, M.; Noseda, M. D.; Cerezo, A. S. Phytochemistry 1989, 28, 2937.

9. Matulewicz, M. C.; Ciancia, M.; Noseda, M. D.; Cerezo, A. S. Phytochemistry 1990, 29, 3407.

10. Ciancia, M.; Matulewicz, M. C.; Finch, P.; Cerezo, A. S. Carbohydr. Res. 1993, 238, 241.

11. Knutsen, S. H.; Myslabodski, D. E.; Larsen, B.; Usov, A. I. Bot. Mar. 1994, 37, 163.

12. Stortz, C. A.; Bacon, B. E.; Cherniak, R.; Cerezo, A. S. Carbohydrate Res. 1994, $261,317$.

13. Miller, I. J:; Wong, H.; Newman, R. H. Austr. J. Chem. 1982, 35, 853.

14. Stevenson, T. T.; Furneaux, R. H. Carbohydr. Res. 1991, 210, 277.

15. Hakomori, S. J. J. Biochem. (Tokyo) 1964, 55, 205.

16. Zaia, J. -Mass Spectrom. Rev. 2004, 23, 161.

17. Harvey, D. J. Rapid. Commun. Mass Spectrom. 1993, 7, 614.

18. Domon, B.; Costello, C. E. Glycoconjugate J. 1988, 5, 397.

19. Dubois, M.; Gilles, K. A.; Hamilton, J. K.; Rebers, P. A.; Smith, F. Anal. Chem. 1956, 28, 350 .

20. Yaphe, W.; Arsenault, G. P. Anal. Biochem. 1965, 13, 143. 
21. Dodgson, K. S.; Price, R. G. Biochem. J. 1962, 84, 106.

22. Park, J. T.; Johnson, M. J. J. Biol. Chem. 1949, 181, 149.

23. Sweet, D. P.; Shapira, R. H.; Albersheim, P. Carbohydr. Res. 1975, 40, 217.

24. Nonami, H.; Fukui, S.; Erra-Balsells, R. J. Mass Spectrom. 1997, 32, 287.

25. Nonami, H.; Tanaka, K.; Fukuyama, Y.; Erra-Balsells, R. Rapid. Commun. Mass Spectrom. 1998, 12, 285.

26. Erra-Balsells, R.; Nonami, H. Environ. Control Biol. 2002, 40, 55. 